\title{
Ketamin - Dexmedetomidine Versus Ketamin - Propofol In Onset Of Action, Hemodinamic Effects And Recovery Time During Gastrointestinal Endoscopy
}

\author{
Alland Angelbarth Kewas *, Muhammad Ihsan**, Fadli Armi Lubis ** \\ *Resident of Anaesthesiology and Intensive Therapy, Faculty of Medicine, Universitas Sumatera Utara, Medan, Indonesia \\ **Departement of Anaesthesiology and Intensive Therapy, Faculty of Medicine, Universitas Sumatera Utara, Medan, Indonesia \\ Email: allandkewas@gmail.com
}

DOI: 10.29322/IJSRP.10.03.2020.p9928

http://dx.doi.org/10.29322/IJSRP.10.03.2020.p9928

\begin{abstract}
Introduction: Gastrointestinal endoscopy causes discomfort and is a burdensome procedure for patients. Providing sedation to relieve patient anxiety and discomfort, improve examination results, and reduce patient memories about the incident. Effective sedation can be assessed by how the drug reaches the onset of rapid sedation, stable hemodynamics and fast recovery time.
\end{abstract}

Objective: This study aims to determine the comparison of the onset of action, hemodynamic effects and recovery time using a combination of intravenous dexmedetomidine ketamine and intravenous propofol ketamine during gastrointestinal endoscopy.

Methods: This study is a randomized clinical trial with a single blind. This research was conducted in December 2019 until January 2020. A total of 30 subjects who underwent gastrointestinal endoscopy were divided into 2 groups. The KD group $(\mathrm{n}=15)$ was given $0.5 \mathrm{mg} / \mathrm{KgBB}$ intravenous sedation $+1 \mathrm{mg} / \mathrm{KgBB}$ Dexmedetomidin / hour syringe pump, the KP group $(\mathrm{n}=15)$ was given $0.5 \mathrm{mg} /$ $\mathrm{KgBB}$ ketamine $+1 \mathrm{mg} / \mathrm{KgBB}$ propofol / hour syringe pump. The start of work is calculated from the entry of the drug until the Ramsay Sedation Scale (RSS) $\geq 4$ is reached. Then the operator starts the endoscopy. Hemodynamics: Mean Arterial Pressure (MAP), Heart Rate, Respiratory Rate, and Oxygen Saturation (SpO2) are measured when in the action room (T0), 5 minutes the procedure starts (T1), 10 minutes the procedure starts (T2), and when endoscopy is complete (T3). The recovery time is calculated from the endoscopy (T3) until the patient reaches the Aldrete score $\geq 9$ (T4). Data were analyzed univariate, bivariate and multivariate. Bivariate data were analyzed by Chi-Square test, Independent T-Test and Mann-Whitney and multivariate data were analyzed by Friedman test.

Results: The onset of action for Ketamine-Propofol group ( $3.7 \pm 1.5$ minutes) was faster than the Ketamine-Dexmedetomidine group $(6.2 \pm 1.6$ minutes) with a significant difference ( $\mathrm{p}<0.05)$. No significant differences in hemodynamics were found: MAP, heart rate, breath frequency and oxygen saturation between Ketamine-Dexmedetomidin and Ketamine-Propofol ( $>$ > 0.05). The recovery time of the Ketamine-Dexmedetomidine group $(11.4, \pm 2.1$ minutes) and in the Ketamine-Propofol group $(11.2, \pm 2.4$ minutes). No significant difference was found in recovery time in the two groups ( $p>0.05$ ). There were no undesirable effects on hemodynamic and respiratory changes in both groups.

Conclusion: Ketamine-Propofol starts faster than Ketamine-Dexmedetomidin. The combination of Ketamine-Dexmedetomidin can maintain haemodynamics during endoscopic procedures as well as the combination of Ketamine-Propofol.

Keyword : Endoskopi gastrointestinal, Ketamin-Dexmedetomidin, Ketamin-Propofol

\section{INTRODUCTION}

EGI is a diagnostic action that is commonly used to find out problems that occur in the upper digestive system, which includes the stomach, esophagus, and small intestine. This action is also known as upper gastrointestinal endoscopy. In the EGI procedure, the doctor uses an instrument called an endoscope or gastroscope to see problems in the upper digestive system. 
EGI creates discomfort and is a burdensome procedure for patients. In general, topical anesthesia in the pharynx is safer as premedication in EGI procedures without sedation. However, patients may experience anxiety, discomfort and pain, and generally cannot tolerate this procedure with topical anesthesia in the pharynx alone. The clinical purpose of providing sedation for EGI is to relieve patient anxiety and discomfort, improve examination results, and reduce patient memories about the event ${ }^{1}$.

Propofol is often used extensively in deep sedation. In the use of propofol as sedation hypotensive side effects are reported and especially is the increased risk of oxygen desaturation in moderate and deep sedation. In general, a single use of propofol or a combination with midazolam and / or fentanyl is one of the widely used regimens for sedation during the EGI procedure ${ }^{2}$. However, the combination of the use of sedation and / or analgesia with propofol can cause some additional risks.

Ketamine maintains hemodynamic stability and sufficient sedation depth during EGI action. Giving ketamine prevents bradycardia, hypotension and achieves sufficient and prolonged sedation. Cardiac toxicity and episodes of psychosis in induction and prolonged recovery time are deficiencies of ketamine. The combination of ketamine and various other sedation drugs helps reduce its side effects ${ }^{3}$.

Dexmedetomidine has sedation, anti-anxiety, and analgesic effects that make cardiorespiratory stability at therapeutic doses. The use can be expanded as an intravenous drug in medical procedures ${ }^{4}$. The use of dexmedetomidine for sedation during gastrocopy is growing. More importantly, the use of dexmedetomidine as sedation in EGI procedures provides respiratory safety and hemodynamic stability ${ }^{2}$.

\section{METHODS}

This study is a randomized clinical trial with a single blind carried out at Haji Adam Malik General Hospital. The subjects of this study were taken by using consecutive sampling technique which means until the sample size is met. In this study, the subjects were patients undergoing Endoscopic Gastrointestinal at the Integrated Diagnostic Installation. After obtaining approval from the Ethics Committee, Faculty of Medicine, University of North Sumatra, based on inclusion criteria (age 18-65 years, Willing to be a research subject, ASA 1-2) and exclusion criteria (Patients with allergies or contraindications to the drugs studied, patients with a history of heart, liver and kidney disease, who are pregnant and other severe illnesses, history of chronic alcohol use, history of abuse of narcotic or sedative analgesia, sufferers of severe psychological or neurological disorders). Drop out criteria if Emergency heart and lung occur in the form of: MAP $<50$, heart rate $<60$ or $>150$ times per minute, respiratory rate $<12$ times per minute, oxygen saturation $<92 \%$ and does not increase with oxygen administration. 30 samples were collected. All subjects were recorded for their identity after the patient arrives in the waiting room of the Integrated Diagnostic Installation (IDT), the patient is re-examined for diagnosis, action plans, infusion access smoothly before signing in and given education of sedation measures to be performed. The patient is taken to the action room, then a standard monitor is installed (blood pressure, heart rate, respiratory rate, oxygen saturation) and records are taken (T0). Both groups of patients were given Ringer Lactat $10 \mathrm{cc} / \mathrm{KgBB}$ crystalloid preloading. Group A was given $0.5 \mathrm{mg} / \mathrm{KgBW}$ intravenous ketamine bolus and $1 \mathrm{mg} / \mathrm{KgBW}$ continuous Dexmedetomidine / hour syringe pump. Group B was given $0.5 \mathrm{mg} / \mathrm{KgBW}$ intravenous bolus and $1 \mathrm{mg} / \mathrm{KgBW}$ continuous propofol / hour syringe pump. Start of Work is the time from the administration of Ketamine to RSS $\geq 4$. Recording hemodynamic monitors (blood pressure, heart rate, respiratory rate, oxygen saturation) and recording T1 5 minutes since the procedure began, T2 10 minutes since the procedure began, T3 action is complete. The recovery time was recorded from the time the EGI procedure was completed until the patient regained consciousness with an Aldrete Score $\geq 9$ (T4). Fentanyl injection of $1 \mathrm{mcg} / \mathrm{KgBB}$ intravenously as resque analgesia. Giving ketamine or dexmedetomidine is stopped after the action is complete. The study was stopped when the research subjects refused to participate further and there were emergency life-threatening airway, heart, lung, brain.. All collected data is tabulated and analyzed statistically. The characteristics of subjects that consist of identity, duration of endoscopy, onset, recovery time and haemodynamic effects were statistically analyzed and presented in the table.

\section{RESULTS}

This study was attended by 30 subjects who met the inclusion criteria. The characteristics of this study were displayed based on age, sex, ASA and BMI classification.

Table 1 Demographic Data Table

\begin{tabular}{cccc}
\hline \multicolumn{1}{c}{ Characteristics } & \multicolumn{2}{c}{ Treatment } & \\
\cline { 2 - 3 } & $\begin{array}{c}\text { Grup A } \\
(\mathrm{n}=15)\end{array}$ & $\begin{array}{c}\text { Grup B } \\
(\mathrm{n}=15)\end{array}$ & p-value \\
\hline Age (years), Mean (SD) & $50,2(15,9)$ & $48(14,6)$ & $0,884^{\mathrm{a}}$ \\
\hline Sex, $\mathrm{n}(\%)$ & $5(33,3)$ & $9(60)$ & $0,143^{\mathrm{b}}$ \\
Male & $10(66,7)$ & $6(40)$ & $0,705^{\mathrm{b}}$ \\
Female & & & \\
\hline ASA classification, $\mathrm{n}(\%)$ & & &
\end{tabular}




\begin{tabular}{rccc} 
ASA-I & $6(40)$ & $5(33)$ & \\
ASA-II & $9(60)$ & $10(67)$ & \\
\hline BMI, Mean (SD) & $23,8(2,8)$ & $23,9(3,3)$ & $0,940^{\mathrm{c}}$ \\
\hline Jumlah & 15 & 15 & \\
\hline
\end{tabular}

a)Mann-Whitney Test, $b$ )Chi-Square, c)Independent samples T-Test

Table 1, patients in group A was 50.2 years with an SD score of 15.9 and group B was 48 years with an SD value of 14.6 years. In group A, there were 5 males (33.3\%) while females had $10(66.7 \%)$. In group B, 9 male sex $(60 \%)$ while female $6(40 \%)$. Group A with ASA-I as many as 6 people (40\%) and ASA-II as many as 9 people (60\%). Group B with ASA-I of 5 people (33\%) and ASA-II of 10 people (67\%). The mean IMT of group A was 23.85 and Group B was 23.94 .

Table 2 Long-standing endoscopic procedures, starting drug work during endoscopy and recovery time after endoscopy after administration of Ketamine-exmedetomidine (Group A) and Ketamine-Propofol (Group B). Treatment

\begin{tabular}{lccc} 
Duration & $\begin{array}{c}\text { Grup A } \\
(\mathrm{n}=15)\end{array}$ & $\begin{array}{c}\text { Grup B } \\
(\mathrm{n}=15)\end{array}$ & p-value \\
\hline $\begin{array}{l}\text { Long endoscopy } \\
\text { procedure, }\end{array}$ & $15(12-40)$ & $15(14-30)$ & $0,255^{\mathrm{a}}$ \\
$\begin{array}{l}\text { Median (Min-Max) } \\
\begin{array}{l}\text { Start working the drug } \\
\text { during endoscopy, } \\
\text { Mean (SD) }\end{array}\end{array}$ & $6,2(1,6)$ & $3,7(1,5)$ & $0,001^{\mathrm{b}}$ \\
\hline $\begin{array}{l}\text { Recovery time after } \\
\text { endoscopy, }\end{array}$ & $11,4(2,1)$ & $11,2(2,4)$ & $0,752^{\mathrm{b}}$ \\
\hline
\end{tabular}

a)Mann-Whitney Test, b)Independent samples T-Test

Table 2, the median value of the endoscopy procedure for group A was 15 minutes with a min-max value of 12-40 minutes while group B was 15 minutes with a min-max value of 14-30 minutes. The mean value of starting the drug at endoscope group A was 6.2 minutes with an SD value of 1.6 minutes while group B was 3.7 minutes with an SD value of 1.5 minutes. The mean recovery time after group A endoscopy was 11.4 minutes with an SD value of 2.1 minutes while group B was 11.2 minutes with an SD value of 2.4 minutes.

The statistical test results of group A endoscopy compared with group B obtained $\mathrm{p}=0.255$, which means that there is no significant relationship between endoscopic procedures between Ketamine-Dexmedetomidine and Ketamine-Propofol. Statistical results of starting drug work during group $\mathrm{A}$ endoscopy compared with group $\mathrm{B} \mathrm{p}=0.001$, which means that there is a significant relationship between drug administration during endoscopy between Ketamine-Dexmedetomidine and Ketamine-Propofol. Statistical test results of recovery time after group A endoscopy compared with group B p $=0.752$, which means that there is no significant association of recovery time after endoscopy between Ketamine-Dexmedetomidine and Ketamine-Propofol.

Table 3 Mean Arterial Pressure (MAP) before and after treatment

\begin{tabular}{|c|c|c|c|c|c|}
\hline \multirow{3}{*}{ Biomarker } & \multirow{2}{*}{\multicolumn{2}{|c|}{$\begin{array}{c}\text { Grup A } \\
(\mathrm{n}=15)\end{array}$}} & \multirow{2}{*}{\multicolumn{2}{|c|}{$\begin{array}{r}\text { Grup B } \\
(n=15)\end{array}$}} & \multirow[t]{3}{*}{ p-value } \\
\hline & & & & & \\
\hline & Mean/Median & SD/Min-Max & Mean & SD & \\
\hline MAP (T0) & 86 & $83-116$ & 92,4 & 9,0 & $0,849^{\mathrm{a}}$ \\
\hline MAP (T1) & 88,4 & 9,6 & 92,3 & 6,2 & $0,197^{\mathrm{b}}$ \\
\hline MAP (T2) & 92,2 & 13,2 & 93,3 & 5,6 & $0,763^{b}$ \\
\hline MAP (T3) & 93 & $69-126$ & 92,5 & 5,5 & $0,672^{\mathrm{a}}$ \\
\hline p-value & & & & & \\
\hline
\end{tabular}

uji a)Mann-Whitney, b)Independent Samples T-Test, c)Friedman, d)ANOVA Repeated

Table 3, Statistical test results know the difference between group A and group B for MAP before the action, 5 minutes after the action, 10 minutes after the action and after the action each p-Value is obtained $\mathrm{p}=0.849(\mathrm{~T} 0), \mathrm{p}=0.197(\mathrm{~T} 1), \mathrm{p}=0.763(\mathrm{~T} 2), \mathrm{p}$ $=0.672$ (T3) which means there is no relationship between the Ketamine-Dexmedetomidine group and the Ketamine-Propofol group against MAP. 
Statistical test results to determine whether or not there is a decrease or increase in the average MAP of group A obtained $\mathrm{p}=$ 0.045, which means there is a significant decrease in MAP of group A over time. Statistical test results to determine whether there is a decrease or increase in the average MAP of group B obtained $p=0.904$, which means there is no significant decrease MAP over time.

Table 4 Heart rate before and after treatment

\begin{tabular}{|c|c|c|c|c|c|}
\hline \multirow[t]{3}{*}{ Biomarker } & \multirow{2}{*}{\multicolumn{2}{|c|}{$\begin{array}{l}\text { Ketamin-Dextomidine } \\
\qquad(\mathrm{n}=15)\end{array}$}} & \multirow{2}{*}{\multicolumn{2}{|c|}{$\begin{array}{l}\text { Ketamin Propofol } \\
\qquad(\mathrm{n}=15)\end{array}$}} & \multirow[t]{3}{*}{ p-value ${ }^{a)}$} \\
\hline & & & & & \\
\hline & Mean/Median & SD/Min-Max & Mean/Median & SD/Min-Max & \\
\hline Heart Rate (T0) & 87,0 & 5,9 & 88 & $68-93$ & $0,730^{\mathrm{b}}$ \\
\hline Heart Rate (T1) & 85 & $69-92$ & 86,4 & 6,0 & $0.900^{\mathrm{a}}$ \\
\hline Heart Rate (T2) & 81,4 & 8,1 & 85,2 & 5,9 & $0,269^{\mathrm{b}}$ \\
\hline Heart Rate (T3) & 86 & $66-92$ & 86 & $61-93$ & $0,602^{\mathrm{a}}$ \\
\hline p-value ${ }^{c}$ & & & & & \\
\hline
\end{tabular}

a)Mann-Whitney, b)Independent Samples T-Test, c)Friedman

Table 4, Statistical test results know the difference between group A and group B for heart rate before the action, 5 minutes after the action, 10 minutes after the action and after the action is obtained each $\mathrm{p}$-value is $\mathrm{p}=0.730(\mathrm{~T} 0), \mathrm{p}=0.900(\mathrm{~T} 1), \mathrm{p}=0.269$ (T2), $\mathrm{p}=0.602$ (T3) which means there is no relationship between the Ketamine-Dextomidine group and the Ketamine-Propofol group to the heart rate.

Statistical test results to determine whether there is a decrease or increase in the average heart rate of group $\mathrm{A}$ obtained $\mathrm{p}=$ 0.019, which means there is a significant decrease in heart rate of group A over time. Statistical test results to determine whether there is a decrease or increase in the average heart rate of Group B p $=0.452$, which means that there is no significant decrease in heart rate over time.

Table 5 Respiratory Rate before and after treatment

\begin{tabular}{|c|c|c|c|c|c|}
\hline \multirow[t]{3}{*}{ Biomarker } & \multirow{2}{*}{\multicolumn{2}{|c|}{$\frac{\text { Ketamin-Dextomidine }}{(\mathrm{n}=15)}$}} & \multirow{2}{*}{\multicolumn{2}{|c|}{$\frac{\text { Ketamin Propofol }}{(\mathrm{n}=15)}$}} & \multirow[t]{3}{*}{$\mathrm{p}$-value } \\
\hline & & & & & \\
\hline & Mean/Median & SD/Min-Max & Mean/Median & SD/Min-Max & \\
\hline Respiratory Rate (T0) & 19,2 & 2,2 & 19,9 & 2,0 & $0,407^{\mathrm{b}}$ \\
\hline Respiratory Rate (T1) & 18 & $16-22$ & 19,3 & 1,9 & $0,314^{\mathrm{a}}$ \\
\hline Respiratory Rate (T2) & 18,0 & 1,6 & 20 & $16-22$ & $0,071^{\mathrm{a}}$ \\
\hline Respiratory Rate (T3) & 18,4 & 1,8 & 20 & $16-21$ & $0,495^{\mathrm{a}}$ \\
\hline
\end{tabular}

a)Mann-Whitney, b)Independent Samples T-Test, c)Friedman

Table 5, Statistical test results know the difference between group A and group B for Respiratory Rate before the action, 5 minutes after the action, 10 minutes after the action and after the action each $p$-Value is obtained $p=0,407(\mathrm{~T} 0), \mathrm{p}=0,314(\mathrm{~T} 1), \mathrm{p}=0,071$ (T2), $\mathrm{p}=0,495$ (T3) which means there is no relationship between the Ketamine-Dexmedetomidine group and the Ketamine-Propofol group against Respiratory Rate.

Statistical test results to determine whether or not there is a decrease or increase in the average MAP of group A obtained $\mathrm{p}=$ 0.047, which means there is a significant decrease in MAP of group A over time. Statistical test results to determine whether there is a decrease or increase in the average Respiratory Rate of group B obtained $p=0.067$, which means there is no significant decrease Respiratory Rate over time.

Table 6 Oxygen Saturation (SpO2) before and after treatment

\begin{tabular}{|c|c|c|c|c|c|}
\hline \multirow[t]{3}{*}{ Biomarker } & Ketami & tomidine & Keta & pofol & \multirow[t]{3}{*}{ p-value ${ }^{a}$} \\
\hline & \multicolumn{2}{|c|}{$(n=15)$} & \multicolumn{2}{|c|}{$(n=15)$} & \\
\hline & Median & Min-Max & Median & Min-Max & \\
\hline $\mathrm{SpO} 2$ (T0) & 99 & $98-99$ & 99 & $98-99$ & 0,671 \\
\hline
\end{tabular}




\begin{tabular}{|c|c|c|c|c|c|}
\hline $\mathrm{SpO} 2(\mathrm{~T} 1)$ & 99 & $97-99$ & 99 & $98-99$ & 0,095 \\
\hline $\mathrm{SpO} 2(\mathrm{~T} 2)$ & 99 & $97-99$ & 99 & 98-99 & 0,374 \\
\hline $\mathrm{SpO} 2(\mathrm{~T} 3)$ & 99 & 98-99 & 99 & 98-99 & 1,000 \\
\hline p-value ${ }^{b}$ & & & & & \\
\hline
\end{tabular}

a)Mann-Whitney, b)Friedman

Table 6, Statistical test results know the difference between group A and group B for Respiratory Rate before the action, 5 minutes after the action, 10 minutes after the action and after the action each $\mathrm{p}$-Value is obtained $\mathrm{p}=0,671$ (T0), $\mathrm{p}=0,095$ (T1), $\mathrm{p}=0,374$ (T2), $\mathrm{p}=1,000$ (T3) which means there is no relationship between the Ketamine-Dexmedetomidine group and the KetaminePropofol group against Oxygen Saturation.

Statistical test results to determine whether or not there is a decrease or increase in the average MAP of group A obtained $p=$ 0.047, which means there is a significant decrease in MAP of group A over time. Statistical test results to determine whether there is a decrease or increase in the average Oxygen Saturation of group B obtained $p=0.067$, which means there is no significant decrease Oxygen Saturation over time.

\section{IV.CONCLUSIONS}

From the results of this study conducted to see comparison of ketamin - dexmedetomidine intravena and ketamin - propofol intravena against working start, hemodinamic effects and recovery time during gastrointestinal endoscopy at Integrated Diagnostic Installation Haji Adam Malik General Hospital, Universitas Sumatera Utara Hospital, it can be concluded that:

1. The administration of Ketamine-Propofol starts faster than Ketamine-Dexmedetomidine

2. There is no difference in the haemodynamic effect between Ketamine-Dexmedetomidine and Ketamine-Propofol.

3. There is no difference in recovery time between Ketamine-Dexmedetomidine and Ketamine-Propofol.

\section{REFERENCES}

1. Farzaneh M, dkk. Midazolam-Ketamin Combination for Moderate Sedation in Upper GI Endoscopy. Original Article: Gastroenterology. JPGN 2012;54: 422-426;

2. Amornyotin S. Intravenous Sedation Techniques for Gastrointestinal Endoscopy. Journal of Gastroenterology and Hepatology Research 2016;5(3);

3. El- Shmaa, dkk. The Efficacy Of Etomidate-Fentanyl Versus Dexmedetomidine-Ketamine For Procedural Sedation And Analgesia During Upper Endoscopy And Biopsy: A Prospective, Randomized Study. Journal of Anesthesia and Clinical Research, 2014,5:12;

4. Chrysostomou C, Schmitt CG. Dexmedetomidime: Sedation, Analgesia And Beyond. Expert opin drug metab toxicpl 2008; 4: 619-627;

\section{AUTHORS}

First Author - Alland Angelbarth Kewas, Post graduate of Anaesthesiology and Intensive Therapy, Faculty of Medicine, Universitas Sumatera Utara, Medan, Indonesia, christian_axeg@ rocketmail.com.

Second Author - Muhammad Ihsan, Anaesthesiology and Intensive Therapy, Faculty of Medicine, Universitas Sumatera Utara, Medan, Indonesia.

Third Author - Fadli Armi Lubis, Anaesthesiology and Intensive Therapy, Faculty of Medicine, Universitas Sumatera Utara,Medan, Indonesia. 